\title{
SUPPORTING INFORMATION FOR \\ Selenium-Mediated Micellar Catalyst: An Efficient Enzyme \\ Model for Glutathione Peroxidase-Like Catalysis
}

Xin Huang, Zeyuan Dong, Junqiu Liu*, Shizhong Mao, Guimin Luo and Jiacong

Shen

Key Laboratory for Supramolecular Structure and Materials of Ministry of Education,

Jilin University, Changchun 130012, P. R. China.

E-mail address: junqiuliu@jlu.edu.cn; Fax: +86-431-5193421. 


\section{Characterization of selenium-mediated micellar catalyst}

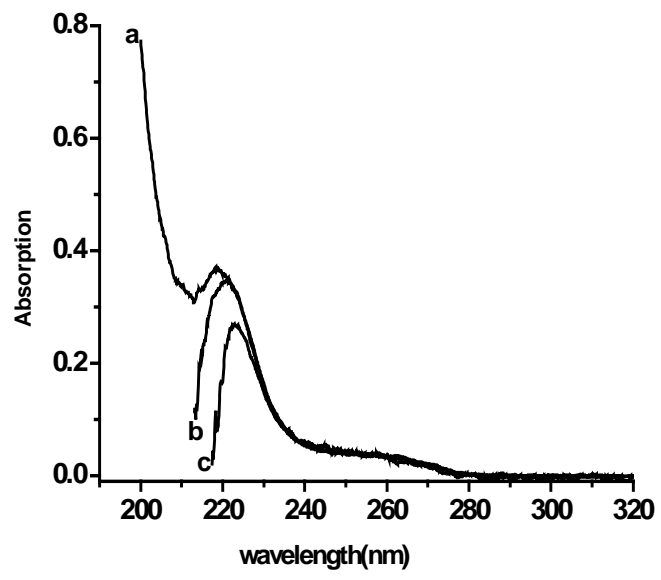

Figure S1. UV spectra of benzeneseleninic acid $(26 \mu \mathrm{M})$ in selenium-mediated micellar catalyst with various concentration of surfactant CTAB. From a to $\mathrm{c}$ the concentrations of CTAB are $0 \mathrm{mM}$ (in water), $3.68 \mathrm{mM}(4 \mathrm{cmc})$ and $5.52 \mathrm{mM}(6 \mathrm{cmc})$ respectively.

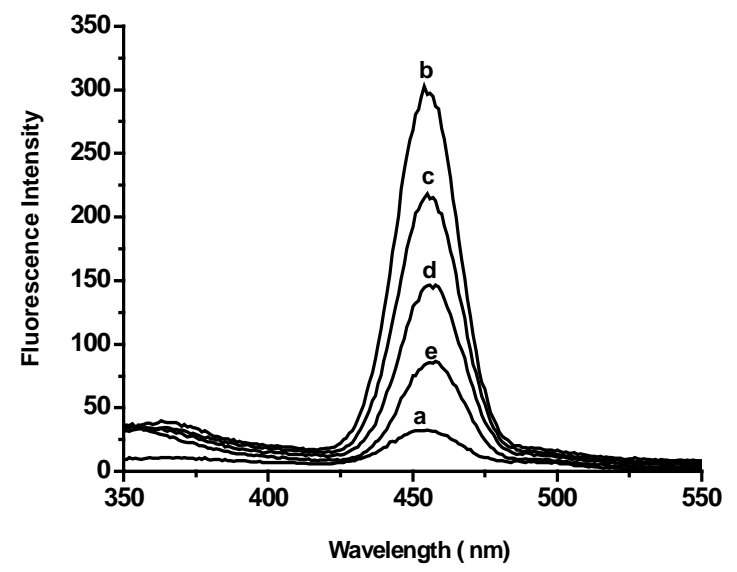

Figure S2. Fluorescence spectra of benzeneseleninic acid in selenium-mediated micellar catalyst with various concentration of surfactant CTAB. From a to e the concentration of CTAB are $0 \mathrm{mM}$ (in water), $0.92 \mathrm{mM}(1 \mathrm{cmc}), 1.84 \mathrm{mM}(2 \mathrm{cmc}), 3.68 \mathrm{mM}(4 \mathrm{cmc})$ and $5.52 \mathrm{mM}(6 \mathrm{cmc})$ respectively. 


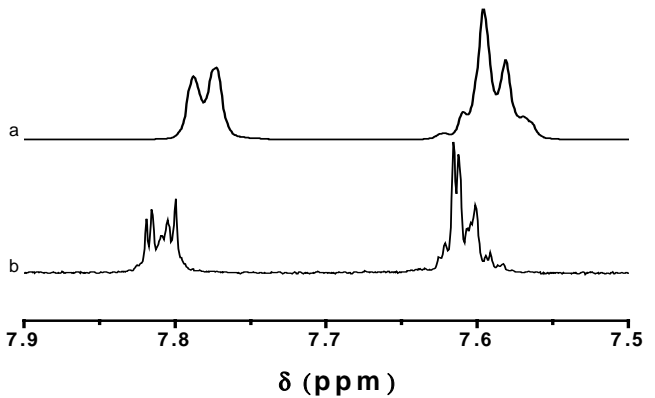

Figure S3. ${ }^{1} \mathrm{H}$ NMR (500 MHz) Spectra of benzeneseleninic acid in the absence (a) and in the presence (b) of micelle in $\mathrm{D}_{2} \mathrm{O}$ at ambient temperature.

\section{Complexation of ArSH and Micelle}

UV Spectra: Keep the concentration of ArSH constant and change the concentration of micelle. The maximum absorption of ArSH (410 nm) shifts were shown in Figure S4.

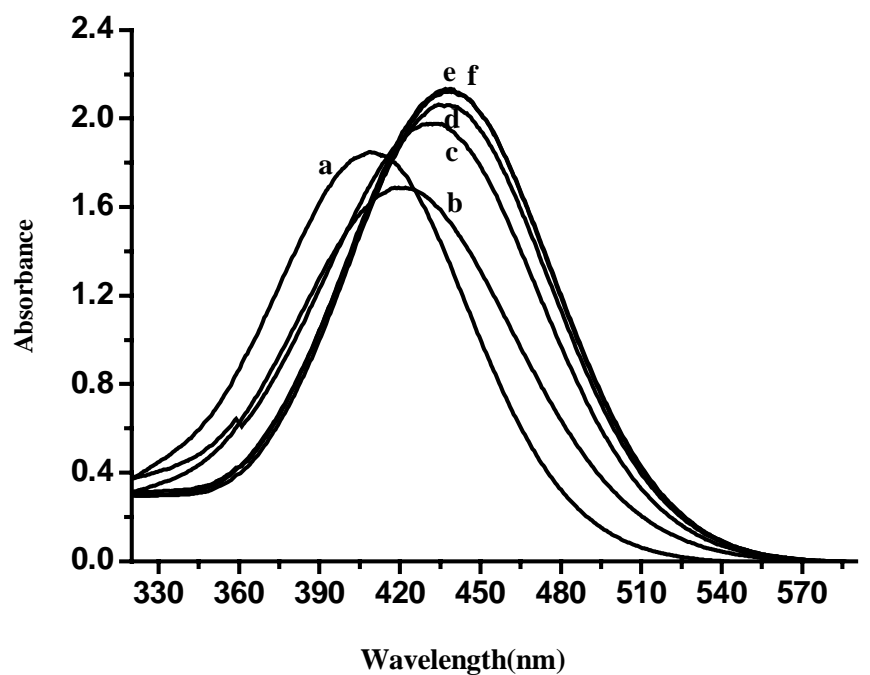

Figure S4. Spectra of ArSH with varying micelle concentration, the concentration of ArSH is $120 \mu \mathrm{M}$, from a to $\mathrm{f}$ the concentration of the micelle is $0,0.92,1.84,2.76,3.61$ and $4.60 \mathrm{mM}$ respectively.

\section{Fluorescence Spectra}




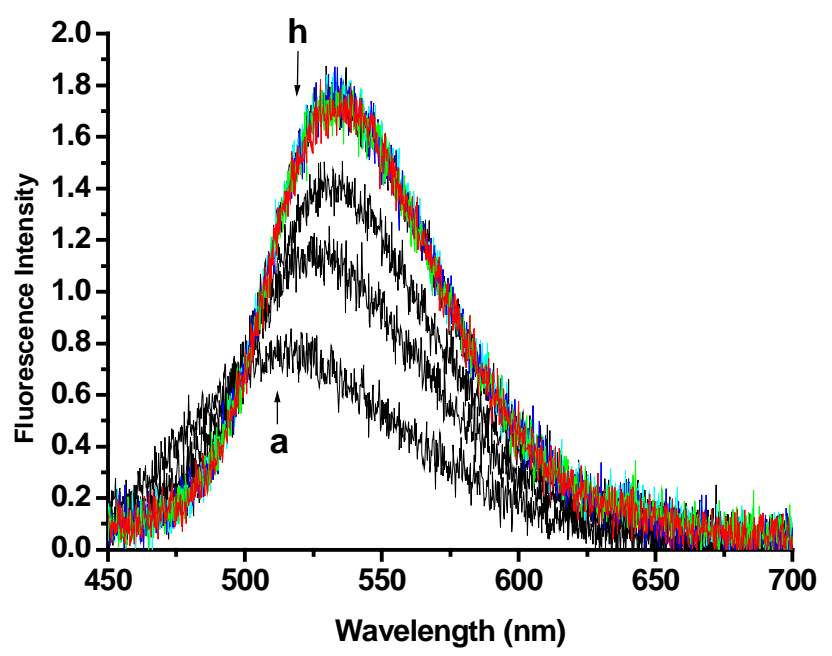

Figure S5. Fluorescence spectra of $\operatorname{ArSH}(0.20 \mathrm{mM})$ in the absence and presence of the micelle in phosphate buffer $(\mathrm{pH} 7.0)$ at $25^{\circ} \mathrm{C}$. The concentration of the micelle was (from a to h): $0,2.00$, $2.37,2.74,3.10,3.46,3.83$ and $4.19 \mathrm{mM}$, respectively. Excitation wavelength was $410 \mathrm{~nm}$.

\section{Complexation of $\mathrm{CuOOH}$ and the Micelle}

UV Spectra: Keep the concentration of $\mathrm{CUOOH}$ constant and change the concentration of micelle. The maximum absorption wavelength of CUOOH shifted as shown in Figure S6.

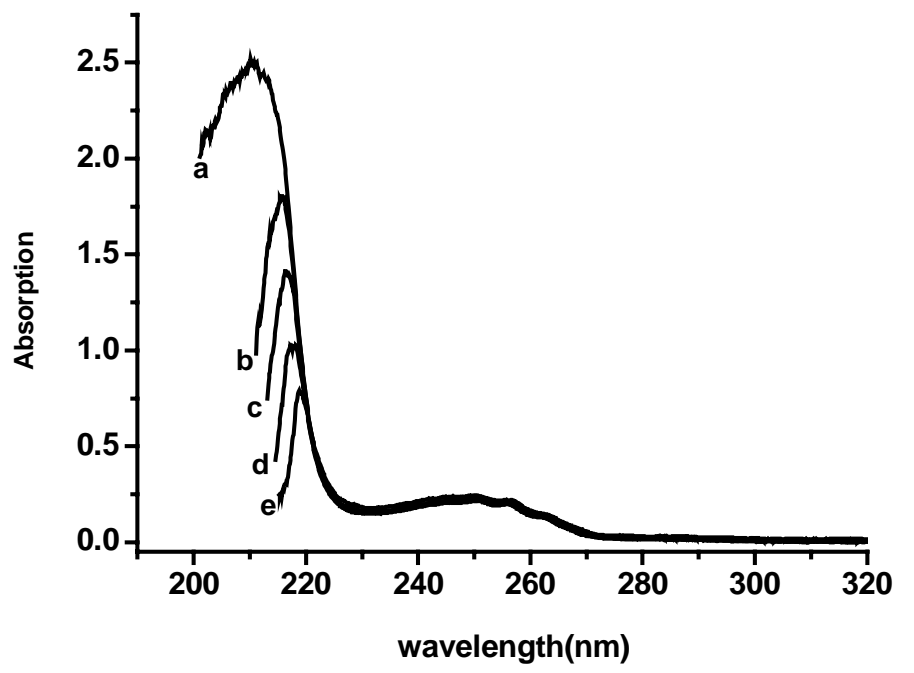

Figure S6. Spectra of CUOOH in varying micelle concentration, the concentration of CUOOH is $250 \mu \mathrm{M}$, from a to e the concentration of micelle is 0 (in water), $0.92 \mathrm{mM}(1 \mathrm{cmc}), 1.84 \mathrm{mM}(2 \mathrm{cmc})$, $3.68 \mathrm{mM}(4 \mathrm{cmc})$ and $7.36 \mathrm{mM}(8 \mathrm{cmc})$ respectively.

\section{Fluorescence Spectra}




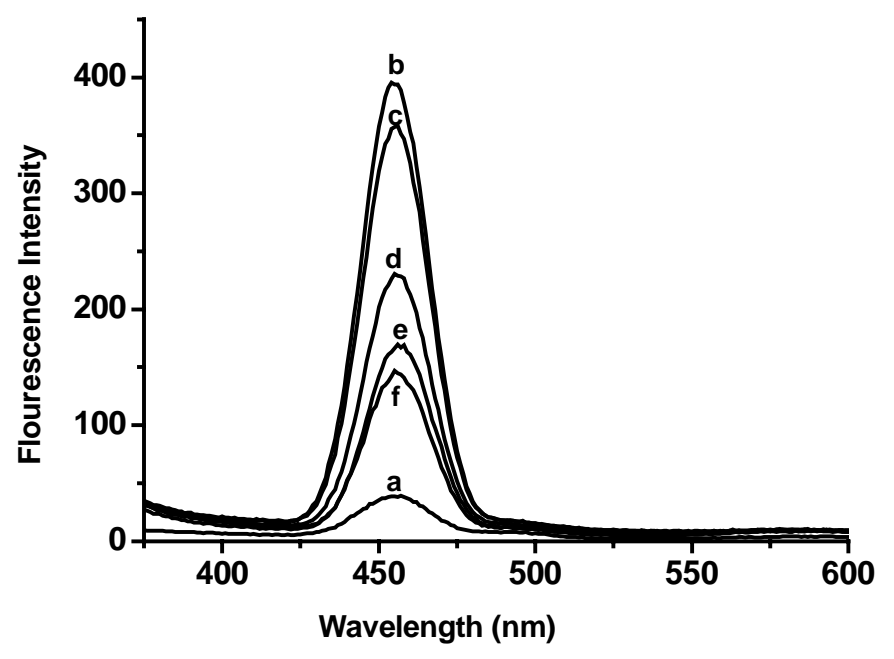

Figure S7. Fluorescence spectra of CUOOH $(0.25 \mathrm{mM})$ in the absence and presence of micelle at $37{ }^{\circ} \mathrm{C}$. The concentration of micelle was (from a to f): 0 (in water), $0.92 \mathrm{mM}(1 \mathrm{cmc}), 1.84 \mathrm{mM}(2$ $\mathrm{cmc}), 3.68 \mathrm{mM}(4 \mathrm{cmc}), 5.52 \mathrm{mM}(6 \mathrm{cmc})$ and $7.36 \mathrm{mM}(8 \mathrm{cmc})$ respectively. Excitation wavelength was $225 \mathrm{~nm}$. 